\title{
19
}

\section{Perceptions About Climate Change Impacts and Adaptation- Case Studies from Indigenous Communities in Northern and Central Australia}

\author{
Kerstin K. Zander, Yiheyis T. Maru, Digby Race, \\ Supriya Mathew and John Rainbird
}

\section{Introduction}

The impact of climate change is one of the most significant environmental challenges facing humans. Australia is likely to face temperature increases in the range $0.6-1.5^{\circ} \mathrm{C}$ by 2030 and $2.2-5^{\circ} \mathrm{C}$ by 2070 compared with the climate of 1980-99 (CSIRO \& Bureau of Meteorology, 2014). Extreme events are likely to become more severe and frequent in many locations across Australia, thus demanding preparatory measures to mitigate the potential risks (Addison, 2013). These extreme events include cyclones, and associated storm surges, riverine and flash flooding, heatwaves, coastal erosion, bushfires and more frequent droughts.

Indigenous communities are likely to feel the consequences of climate change in terms of maintaining their health and wellbeing, and outdoor living and housing comfort (Green et al., 2010). Indigenous peoples' ability to pursue education and employment opportunities, and the viability of community businesses are also likely to be affected by increases in intensity and frequency of extreme events such as heatwaves and flash flooding, 
which can cut off transport and communication to remote communities. The strong dependence of many remote Indigenous Australians on their traditional country for food (Altman, 2004), health (Garnett et al., 2009) and culture (Altman et al., 2007) may further increase the vulnerability ${ }^{1}$ of Indigenous communities to climate change (Adger et al., 2005; Green et al., 2010).

There is a growing body of literature on understanding how Indigenous communities perceive, and might adapt to, climate change, globally (Berkes \& Jolly, 2001; Sakakibara, 2008; Byg \& Salick, 2009; Turner \& Clifton, 2009) and in Australia (Green et al., 2010; Petheram et al., 2010; Petheram et al., 2015; Bardsley \& Wiseman, 2012; Bird et al., 2013; Zander et al., 2013; Maru et al., 2014; Race et al., 2014). Recent studies in this area increasingly refer to adaptive capacities derived as a combination of vulnerabilities (e.g. socioeconomic disadvantage, distant governance and services for remote communities) and resilience (e.g. experience living in uncertain and harsh climates) (Petheram et al., 2010; Maru et al., 2014). In Australia, remote Indigenous communities typically have strong social networks (McAllister et al., 2008), a unique relationship to their country and considerable family and kinship responsibilities (Salmon, 2000; Burgess et al., 2009). These can create opportunities to improve their resilience (e.g. high mobility could allow relocation) to climaterelated risks and increasing vulnerabilities (e.g. overcrowding and health implications). Adaptation should be considered as a dynamic, long-term, transitory and transitional process that involves repeated decisions, better described as adaptation pathways (Maru \& Stafford Smith, 2014).

To inform Indigenous peoples' pathways to adaptation, there is a need for understanding what impacts climate change and extreme events have on Indigenous communities, how climate change-related changes and impacts are perceived and what might be feasible adaptation responses. In this chapter, we aim to present a synthesis of research conducted in four case studies (see Figure 19.1) that address these issues. We focus on the jurisdictions with the highest proportion of Indigenous people in Australia-the Northern

1 We used Intergovernmental Panel on Climate Change definitions as follows: adaptation = 'adjustment in natural or human systems in response to actual or expected climatic stimuli or their effects, which moderates harm or exploits beneficial opportunities'; vulnerability = 'the degree to which a system is susceptible to, and unable to cope with, adverse effects of climate change, including climate variability and extremes'; resilience = 'ability of a social or ecological system to absorb disturbances while retaining the same basic structure and ways of functioning, the capacity for self-organisation, and the capacity to adapt to stress and change' (Intergovernmental Panel on Climate Change, 2007). 
Territory (NT) with nearly 30 per cent and the Torres Strait Islands in northern Queensland with 79 per cent of their populations identifying as Indigenous or Torres Strait Islanders. The NT (both coastal and central desert areas) and north Queensland including low-lying islands of Torres Strait are prone to extreme weather events (Hennessy et al., 2007).

Three case studies are from the NT: 1) Lajamanu at the northern end of the Tanami Desert, 2) town camps of Alice Springs in Central Australia and 3) Yirrkala in East Arnhem Land. In all three case studies, in-depth interviews, focus group discussions and workshops were conducted with community members, using a range of participatory methods in collaboration with local Indigenous researchers. The fourth case study is from Queensland and presents a Human Development Index (HDI) and adaptation implication analysis for the people in the Torres Strait region. A more detailed description of the methodology for the research in Lajamanu and Alice Springs (see Race et al., 2014; Race et al., 2016), Yirrkala (Petheram et al., 2010; Zander et al., 2013) and the Torres Straits (Butler et al., 2014) is provided in the cited literature. The research for the case studies was conducted at different times with varying foci and data collection methods (see Table 19.1).

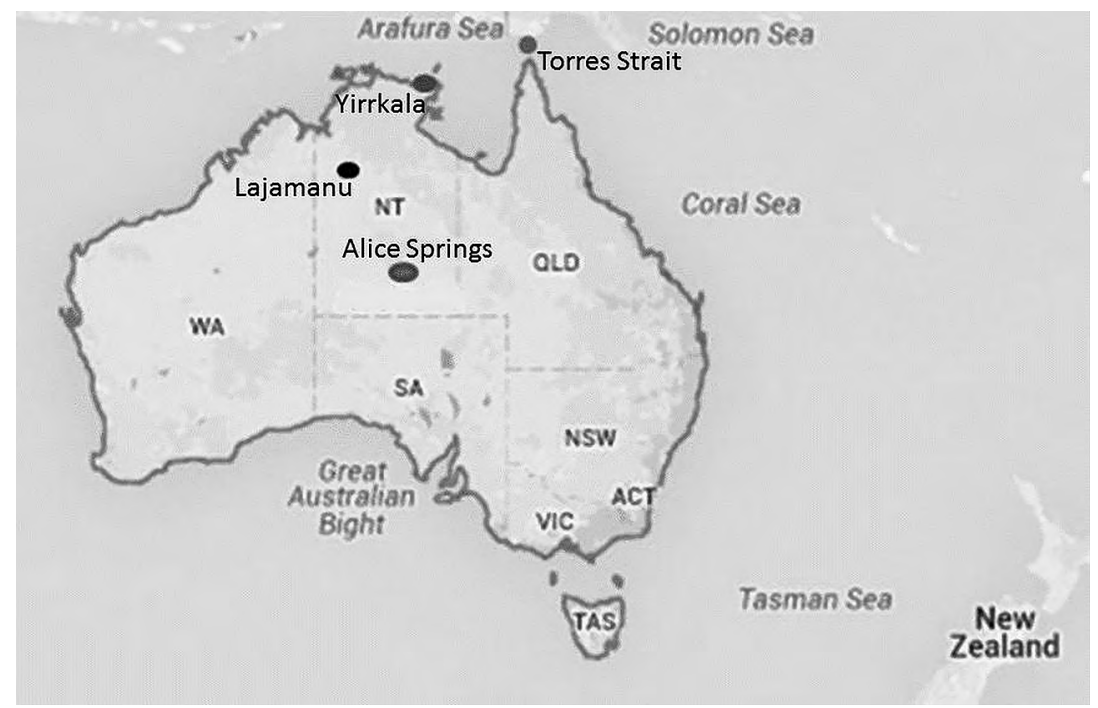

Figure 19.1: Locations of the case study regions-communities in Lajamanu, Yirrkala and Torres Strait and town camps around Alice Springs.

Source: Authors' research. 
Table 19.1: Details of the four case studies.

\begin{tabular}{|c|c|c|}
\hline Case study & Objectives & Methods \\
\hline $\begin{array}{l}\text { Lajamanu } \\
\text { community } \\
\text { case study } \\
\text { and } \\
\text { Alice Springs } \\
\text { town camps }\end{array}$ & $\begin{array}{l}\text { To gather information } \\
\text { about: } \\
\text { 1. major weather } \\
\text { changes (over } \\
\text { seasons and over } \\
\text { years) in study } \\
\text { participants' lifetimes } \\
\text { 2. major weather } \\
\text { events that affect } \\
\text { the participants } \\
\text { 3. adaptive strategies } \\
\text { used to cope with } \\
\text { extreme weather. }\end{array}$ & 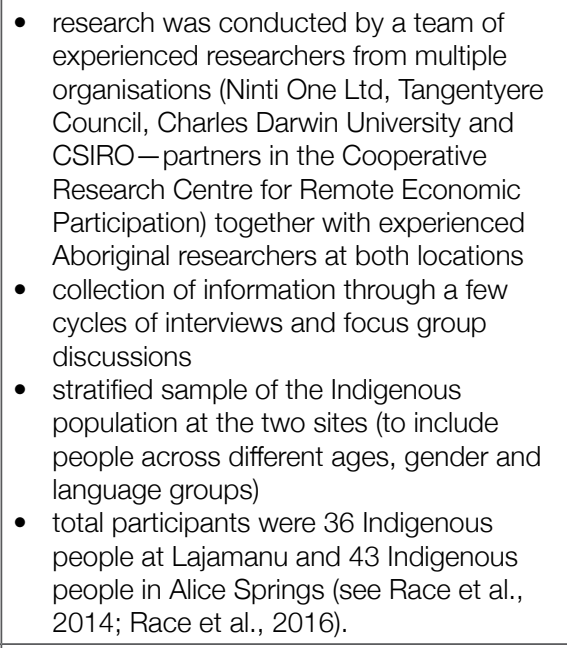 \\
\hline Yirrkala & $\begin{array}{l}\text { To understand } \\
\text { Indigenous peoples' } \\
\text { perception of climate } \\
\text { change and associated } \\
\text { coping strategies now } \\
\text { and in the future to } \\
\text { integrate those into } \\
\text { mainstream in planning } \\
\text { adaptation policy. }\end{array}$ & $\begin{array}{l}\text { - in-depths interviews conducted by } \\
\text { Indigenous co-researchers and workshops } \\
\text { - } \quad \text { facilitated by Indigenous co-researchers } \\
\text { by the research situation (contacts and } \\
\text { available participants) and later guided by } \\
\text { emergent data and theory, in a process of } \\
\text { 'theoretical sampling' } \\
\text { - total number of participants was } 21 \\
\text { - four workshops - two with a total of nine } \\
\text { male Indigenous land/sea rangers from } \\
\text { the Dhimurru Aboriginal Corporation and } \\
\text { two workshops with a total of } 12 \text { female } \\
\text { participants from a women's organisation } \\
\text { and local households } \\
\text { - use of visual techniques to support } \\
\text { - discussions } \\
\text { data collected over two years (2008-10). }\end{array}$ \\
\hline $\begin{array}{l}\text { Torres Strait } \\
\text { region }\end{array}$ & $\begin{array}{l}\text { 1. assess regional } \\
\text { resilience } \\
\text { 2. explore potential } \\
\text { future scenarios in } \\
\text { the face of climate } \\
\text { and other changes } \\
\text { 3. identify adaptation } \\
\text { options. }\end{array}$ & $\begin{array}{l}\text { - two regional and three community-level } \\
\text { workshops conducted between July } 2012 \\
\text { and December } 2014 \\
\text { - } \text { surveys on perceptions of the meaning, } \\
\text { elements and status of resilience of } \\
\text { communities, the region, climate change } \\
\text { and other social and environmental } \\
\text { changes } \\
\text { - analysis of a Human Development Index } \\
\text { (HDI) for the Torres Strait region for global } \\
\text { comparison } \\
\text { - HDI combined with } 2006 \text { Australian Bureau } \\
\text { of Statistics census data for Torres Strait } \\
\text { region. }\end{array}$ \\
\hline
\end{tabular}




\section{Case Study: Yirrkala}

Yirrkala is situated in North East Arnhem Land (see Figure 19.1) with a population of approximately of 800 . This area, as part of tropical Northern Australia, is expected to become hotter, experience sea level rise and more extreme cyclonic events and associated storm surges. Sea levels rose 7-10 mm per year along Australia's northern coastline between 1993 and 2009, about three times the rate of sea level rise along the southern and eastern coastlines (CSIRO \& Bureau of Meteorology, 2014). Many off-shore islands, wetland areas and coastlines are likely to be vulnerable to erosion and saltwater intrusion (Green, 2008) leading to significant negative impacts on the distribution of plant and animal species (Dunlop \& Brown, 2008).

The Indigenous people in this case study area are referred to as Yolngu and consist of more than 50 Indigenous clans. Their language group, Yolngu Matha, comprises about 12 different dialects (Omniglot, 2009). The conducted research was in collaboration with local co-researchers and the Dhimurru Aboriginal Corporation (ranger group). We conducted in-depth interviews and a series of workshops (see Table 19.1). Using visual techniques such as drawing maps and diagrams, participatory sculpting and participant-generated photography (see Petheram et al., 2010; Petheram et al., 2011), respondents were asked to identify changes in their environment (which also included social/political changes) that they have noticed. Causes of these changes were then discussed, of which climate change was one.

Workshop participants always talked about climate change impacts in relation to non-climate (social) issues and observed landscape changes have almost always been attributed to a combination of climate change and mining (Yirrkala and surrounding communities are very close to a bauxite mine) and development (e.g. increasing tourism). When discussing possible ways to adapt, people in Yirrkala also invariably linked climate change to current wider problems such as lack of employment opportunities, housing and facilities for the youth and violence (see Petheram et al., 2010). However, many said that their current problems will worsen as exposure to extreme weather events increase. Rather than responding to a top-down approach, Indigenous people in Yirrkala stressed the importance of dealing with climate change adaptation in culturally acceptable ways by fostering self-sufficiency, independence 
and empowerment. Some also stressed the importance of observing and knowing the environment (their traditional country) in enabling people to adapt to climatic changes and, more broadly, any environmental change (e.g. changes in seasons, abundance of animals, fires and existence of plants used for food).

\section{Case Study: Lajamanu}

Lajamanu is a small remote town in the NT with the majority of its 650 residents being Indigenous. The projected climate change indicates there will be an increase in temperatures, with more hot days and extended periods of warm temperatures and fewer frosts for the northern rangelands region, which includes both Lajamanu and Alice Springs. Rainfall projections are unclear for this region. ${ }^{2}$ As in most remote Australian locations, occurrences of extreme events (e.g. floods and cyclones) can result in damage to infrastructure, road closures and spread of diseases.

During the survey and focus group discussions with the participants at Lajamanu, people indicated that most of them are deeply aware of the short-term weather and long-term trends of the climate where they live. The surrounding natural environment remains an important indicator of the local climate, even when the environment is in various stages of alteration (e.g. dams used to trap and store surface water, thereby affecting creeks and waterholes) and degradation (e.g. overgrazing by feral animals and prevalence of weeds). Not surprisingly, people who spend more time living and working outdoors (e.g. hunting and gathering wild food in the surrounding country or employed as rangers to manage the surrounding natural resources) reported more detailed experiences and insights about the climate and changes to their country. ${ }^{3}$ The results of this research indicated that the rich and deeply embedded traditional ecological knowledge (TEK) held by remote Indigenous communities is affected by the frequency and nature of access to their country. Recent policy and organisational changes are formalising avenues for this TEK to be shared and documented (according to cultural protocols) and included in

2 See northern rangelands Coupled Model Intercomparison Project data, www.climatechange inaustralia.gov.au/en/.

3 'Country' is a term used by Aboriginal people to refer to the land to which they have a long cultural connection to and their place of Dreaming (see australianmuseum.net.au/glossary-indigenous-australiaterms\#sthash.bnq5gbOw.dpuf). 
decision-making in relation to natural resource management. Participants in the focus group discussions acknowledged that the Aboriginal Ranger Groups are one such avenue, where small teams of men and women from the local community are employed to manage the surrounding natural environment.

\section{Case Study: Alice Springs Town Camps}

Alice Springs is an established town in Central Australia with a population of about 28,000, which fulfils an important role as a service hub providing education, employment, health, welfare and financial services to the wider population in the Central Australian region. About 19 per cent of the Alice Springs population is Indigenous. It has a semi-arid climate but is still prone to flash flooding, which can result in the outbreak of infectious diseases, bushfires following the increase in vegetation, damage to infrastructure and disruption to transport links (Beer et al., 2013). The projected increase in the number of hotter days is likely to result in health-related challenges, such as heat stress affecting vulnerable members of communities such as the elderly and those with poor health (see Webb et al., 2014). Climate change is also expected to affect the pastoral and tourism industries (Beer et al., 2013; Race, 2015).

Participants in the research conducted in the Alice Springs town camps (public housing for Aboriginal communities in Alice Springs) mentioned that they had observed many changes to the climate (e.g. hotter and longer summers and more variable rainfall) and natural surroundings (e.g. more weeds and less bush food). The respondents indicated that modern housing and associated services (e.g. reliable supply of fresh water) provided a comfortable adaptation to heat in comparison to what was available to them prior to the 1990s. Their adaptive strategies mainly focused on: 1) energy intensive measures (e.g. air conditioners) to moderate building temperatures at comfortable levels; 2 ) housing designs as a shelter against extreme weather; and 3) movement to communal buildings such as shopping or art centres to escape harsh weather. They also mentioned gathering under tree shade and hosing the ground as heat stress mitigation measures. The strong social networking interests of these communities have also been highlighted in their adaptation preferences 
(e.g. gathering under the shade of trees and visiting shopping or art centres). Participants noted an increased reliance on modern technology to adapt to the increasing heat in Alice Springs.

\section{Case Study: Torres Strait Region}

The Torres Strait region is part of the northern border of Australia that stretches from the tip of Cape York to the south-western coast of Papua New Guinea. The region has 18 communities with 17 islands supporting permanent settlements (Foreign Affairs, Defence and Trade References Committee, 2010). The Torres Strait region is home to about 7,500 people of whom 84 per cent are of Torres Islander and Aboriginal origin (ABS, 2012). The Torres Strait Islander people have deep connections with and extensive local knowledge of their land and sea (Foreign Affairs, Defence and Trade References Committee, 2010; Butler et al., 2012).

Geographic location and island characteristics, cultural factors and socioeconomic conditions put the Torres Strait Islands at high risk of impacts from climate change and associated increases in frequency and intensity of extreme weather events (Green et al., 2010). Some communities on low-lying islands, especially in the central coral cay islands of Masig, Poruma, Iama and Warraber and northwest mud islands of Boigu and Saibai, are already experiencing inundation and erosion impacts of sea level rise and storm surges. Communities are very concerned by their current experiences and potential impacts of climate on the long-term liveability of their islands and their ability to undertake traditional livelihoods including hunting and fishing (Green et al., 2010; McNamara \& Westoby, 2011). Potential community dislocation as result of climate change will likely have negative impacts on the physical and mental health of Torres Strait Islander people as it disrupts close attachments of communities to country and challenges their strong view of community health and wellbeing connections to the state of their land and sea country (Green \& Minchin, 2014). Potential impacts of climate change (Butler et al., 2012) include:

- increasing coastal erosion and major damage to settlement infrastructure including houses, transport facilities, sewerage, water and power plants with risk of mortality, morbidity and disruption of livelihood and potential dislocations 
- inundation of cemeteries and other culturally sacred sites with potential for a high level of physical and psychological health implications

- increase in insect-borne diseases due to change in favourable climate and breeding conditions

- changes in breeding patterns, abundance and location of important totemic (e.g. dugong and turtle) and other animals and plants with implication for nutrition, health and community wellbeing

- increased risk of heat-related impacts such as heat stress, water shortage and bushfire risk.

Communities have received urgent support from state and federal governments to build sea walls as an adaptation response to reduce exposure to sea level rise. In recent participatory adaptation and resilience planning work carried out by the Torres Strait Regional Authority (2016), community leaders recognised the importance of immediate hard adaptation responses (those involving physical infrastructure). However, they also noted the widespread health and socioeconomic disadvantage and high level of dependence on welfare as core causes of weakening culture, thus adding to the social vulnerability of these communities to climate change impacts.

Our calculations of HDI for the Torres Strait region puts the region's disadvantage into a global perspective. The HDI had a scale ranging from zero (lowest) to one (highest), based on a country's life expectancy, adult literacy and school enrolment in the particular year. UNDP (2009) ranked 187 nations in 2007 and used ABS (2006) data for Australia, which ranked second. Our estimate of the HDI score for the Torres Strait Islands resulted in 0.736, ranking 110th out of 187 and close in ranking to Fiji and other developing countries. The score for Indigenous Torres Strait Islanders indicated a gap of 0.274 in favour of the nonIndigenous population in the Torres Strait region, showing a significant disparity in the health and the socioeconomic conditions of Indigenous and non-Indigenous communities.

The Steering Committee for the Review of Government Service Provision (2014) report indicated that there has been slight improvement in life expectancy, average income and post-secondary education outcomes. However, Indigenous rate of disability and chronic diseases remains very high, mental health problems and adult imprisonment rates have worsened and no change has occurred in juvenile detention, family and community violence and literacy and numeracy results. 
Climate change impacts already evident, particularly in the low-lying islands, may worsen the health and socioeconomic disadvantage of Torres Strait Islander people and the worsening conditions may, in turn, amplify the vulnerability of communities to climate change and associated increases in the severity of impacts of extreme weather events. This forms a trap that requires a transformative action (Maru et al., 2012). A transformative action involves addressing the root cause to achieve a substantial qualitative and systemic change in the system. Torres Strait Islander communities have adapted to changes in climate in the past and still retain many elements of resilience in their culture, local language and traditional knowledge. Efforts for transformation must build on these resilient elements. However, transformation will require addressing root causes of current health and other socioeconomic conditions and a substantial reduction in welfare dependence of Torres Strait Islander communities as in the other case studies.

\section{Concluding Remarks}

The research conducted in the four case studies indicates the importance of building on the strengths of the local community (e.g. existing resources, social networks and traditional knowledge) to explore and develop feasible adaptation options, rather than introducing adaptation measures that may be effective elsewhere for different populations. The social capital cultural values and knowledge of the Indigenous communities that need to underpin efforts to build the adaptive capacity to climate change are often undervalued by outside researchers, policymakers and service providers. While modern buildings can provide immediate relief from extended periods of hot weather or storms (e.g. shopping centres), these can be expensive to operate and may not be affordable to operate as currently practised over the long term for the highly dispersed population across Central Australia. The example of the Aboriginal Ranger Groups (described above) are creating a new adaptation knowledge that blends TEK with contemporary science and equipment that simultaneously addresses vulnerability (e.g. using contemporary technology to record and analyse changes in the local environment and using modern equipment and vehicles to control pest animals and plants to enhance the health of the native biodiversity) and builds resilience (e.g. draws on knowledge and wisdom of Elders and builds the skills and knowledge of younger generations about how to care for their country) amid complex changes. 
As such, learning how best to blend the existing strengths of remote Indigenous communities with that offered by outsiders (e.g. individuals, organisations and governments) is most likely to afford an effective way forward so that remote Indigenous communities can build their resilience to the changes they confront.

Despite the exposure to different impacts of climate change and associated extreme events, there is communality and similarity in the level of health and social wellbeing disadvantages and welfare dependency of communities across all four case studies, which is at the core their heightened sensitivity and low capacity to adapt. We argue that a stronger understanding of the cultural and social capital within remote Indigenous communities, particularly those still strongly framed by traditional culture, can enhance the development of bottom-up approaches for effective climate adaptation (e.g. approaches initiated, developed and supported by local residents). In three communities, Indigenous people pointed out the need for integrating climate change policies into other mainstream policies. However, Indigenous communities in all four case studies face multiple and immediate socioeconomic problems such as lack of education, jobs and housing, violence, and medical problems. Therefore, climate change policies and responses to climate risks should not be implemented in isolation from other policies that community members wish the government to pursue to alleviate the more urgent problems (Petheram et al., 2010; Mathew et al., 2012).

This means paying attention to multiple immediate issues while simultaneously addressing the root causes of vulnerability of Indigenous communities to climate change and associated extreme events. An attention only to immediate community issues poses the risk of resulting in maladaptive actions. The adaptation decision process in Indigenous communities should simultaneously address both short- and long-term issues and combine incremental and transformation actions as suggested by Maru et al. (2014). The balance of attention to incremental (e.g. short-term options such as use of electric air conditioners to adapt to heat stress and community education) and transformational adaptation actions (e.g. transforming to renewable energy) that need to be given in building adaptation pathways will depend on whether a community is in a maladaptive or an adaptive space (Wise et al., 2014). While incremental adaptation has a place, the significant health and socioeconomic disadvantage and the welfare dependence are such that transformation 
options that build on the resilient elements of the communities are required to effectively address the combination of changes (including climate change) affecting remote Indigenous communities in Northern Australia.

\section{References}

Addison, J. (2013). Impact of climate change on health and wellbeing in remote Australian communities a review of literature and scoping of adaptation options (CRC-REP Working Paper CW014). Alice Springs, NT: Ninti One Ltd.

Adger, W. N., Hughes, T. P., Folke, C., Carpenter, S. R. \& Rockström, J. (2005). Social-ecological resilience to coastal disasters. Science, 309(5737), 1036-1039.

Altman, J. (2004). Economic development and Indigenous Australia: Contestations over property, institutions and ideology. Australian Journal of Agricultural and Resource Economics, 48(3), 513-534.

Altman, J., Buchanan, G. J. \& Larsen, L. (2007). The environmental significance of the Indigenous estate: Natural resource management as economic development in remote Australia (Discussion Paper No. 286). Canberra, ACT: ANU.

Australian Bureau of Statistics (ABS). (2006). Population characteristics, Aboriginal and Torres Strait Islander Australians, 2006 (Cat. No. 4713.0). Canberra, ACT: ABS.

Australian Bureau of Statistics (ABS). (2012). 2011 census of population and housing. Aboriginal and Torres Strait Islander peoples (Indigenous) (Cat. No. 2002.0). Canberra, ACT: ABS.

Bardsley, D. K. \& Wiseman, N. D. (2012). Climate change vulnerability and social development for remote Indigenous communities of South Australia. Global Environmental Change, 22(3), 713-723.

Beer, A., Tually, S., Kroehn, M., Martin, J., Gerritsen, R., Taylor, M., ... Law, J. (2013). Australia's country towns 2050: What will a climate adapted settlement pattern look like? Gold Coast, Qld: National Climate Change Adaptation Research Facility.

Berkes, F. \& Jolly, D. (2001). Adapting to climate change: Social-ecological resilience in a Canadian western arctic community. Conservation Ecology, 5(2), Article 18. 
Bird, D., Govan, J., Murphy, H., Harwood, S., Haynes, K., Carson, D., ... Larkin, S. (2013). Future change in ancient worlds: Indigenous adaptation in Northern Australia. Gold Coast, Qld: National Climate Change Adaptation Research Facility.

Burgess, P.C., Johnston, F.H., Berry, H.L., McDonnell, J., Yibarbuk, D., Gunabarra, C., Mileran, A. \& Bailie, R.S. (2009). Healthy country, healthy people: The relationship between Indigenous health status and caring for country. Medical Journal of Australia, 190(10), 567-572.

Butler, J. R., Tawake, A., Skewes, T., Tawake, L. \& McGrath, V. (2012). Integrating traditional ecological knowledge and fisheries management in the Torres Strait, Australia: The catalytic role of turtles and dugong as cultural keystone species. Ecology and Society, 17(4), 1-19.

Butler, J. R., Skewes, T., Mitchell, D., Pontio, M. \& Hills, T. (2014). Stakeholder perceptions of ecosystem service declines in Milne Bay, Papua New Guinea: Is human population a more critical driver than climate change? Marine Policy, $46,1-13$.

Byg, A. \& Salick, J. (2009). Local perspectives on a global phenomenonclimate change in eastern Tibetan villages. Global Environmental Change, 19(2), 156-166.

Commonwealth Scientific and Industrial Research Organisation (CSIRO) \& Bureau of Meteorology. (2014). State of the climate 2014. Retrieved from www. bom.gov.au/state-of-the-climate/documents/state-of-the-climate-2014_lowres.pdf?ref=button

Dunlop, M. \& Brown, P. R. (2008, February). Implications of climate change for Australia's National Reserve System: A preliminary assessment. Canberra, ACT: Department of Climate Change.

Foreign Affairs, Defence and Trade References Committee. (2010, November). The Torres Strait: Bridge and border. Canberra, ACT: Commonwealth of Australia. Retrieved from www.aph.gov.au/ $/$ media/wopapub/senate/committee/fadt_ ctte/completed_inquiries/2010-13/torresstrait/report/report.ashx

Garnett, S. T., Sithole, B., Whitehead, P. J., Burgess, C. P., Johnston, F. H. \& Lea, T. (2009). Healthy country, healthy people: Policy implications of links between Indigenous human health and environmental condition in tropical Australia. The Australian Journal of Public Administration, 68(1), 53-66.

Green, D. (2008). Garnaut climate change review. Climate impacts on the health of remote northern Indigenous communities. Sydney, NSW: University of New South Wales. 
Green, D., Alexander, L., Mclnnes, K., Church, J., Nicholls, N. \& White, N. (2010). An assessment of climate change impacts and adaptation for the Torres Strait Islands, Australia. Climatic Change, 102(3), 405-433.

Green, D. \& Minchin, L. (2014). Living on climate-changed country: Indigenous health, well-being and climate change in remote Australian communities. EcoHealth, 11(2), 263-272.

Hennessy, K., Fitzharris, B., Bates, B. C., Harvey, N., Howden, M., Hughes, L., ... Warrick, R. (2007). Australia and New Zealand climate change 2007: Impacts, adaptation and vulnerability. In M. L. Parry, O. F. Canziani, J. P. Palutikof, P. J. van der Linden \& C. E. Hanson (Eds), Contribution of working group II to the fourth assessment: Report of the intergovernmental panel on climate change. Cambridge, England: Cambridge University Press.

Intergovernmental Panel on Climate Change. (2007). Climate change 2007, glossary. Retrieved from www.ipcc.ch/site/assets/uploads/2019/01/SYRAR5Glossary_en.pdf

Maru, Y. T., Chewings, V. \& Sparrow, A. (2012). Climate change adaptation, energy futures and carbon economies in remote Australia: A review of the current literature, research and policy (CRC-REP Working Paper CW005). Alice Springs, NT: Ninti One Ltd.

Maru, Y. T. \& Stafford Smith, M. (2014). Reframing adaptation pathways. Global Environmental Change, 28, 322-324.

Maru, Y. T., Stafford Smith, M., Sparrow, A., Pinho, P. F. \& Dube, O. P. (2014). A linked vulnerability and resilience framework for adaptation pathways in remote disadvantaged communities. Global Environmental Change, 28, $337-350$.

Mathew, S., Trueck, S. \& Henderson-Sellers, A. (2012). Kochi, India case study of climate adaptation to floods: Ranking local government investment options. Global Environmental Change, 22, 308-319.

McAllister, R. R. J., Cheers, B., Darbas, T., Davies, J., Richards, C., Robinson, C. J., Ashley, M., Fernando, D. \& Maru, Y. T. (2008). Social networks in arid Australia: A review of concepts and evidence. Rangeland Journal, 30, 167-176.

McNamara, K. E. \& Westoby, R. (2011). Local knowledge and climate change adaptation on Erub Island, Torres Strait. Local Environment, 16, 887-901.

Omniglot. (2009). Yolngu (Yolyu matha). Retrieved from www.omniglot.com/ writing/yolngu.php 
Petheram, L., High, C., Campbell, B. M. \& Stacey, N. (2011). Lenses for learning: Visual techniques in natural resource management. Journal of Environmental Management, 92, 2734-2745.

Petheram, L., Stacey, N. \& Fleming, A. (2015). Future sea changes: Indigenous women's preferences for adaptation to climate change on South Goulburn Island, Northern Territory (Australia). Climate and Development, 7, 339-352.

Petheram, L., Zander, K. K., Campbell, B., High, D. \& Stacey, N. (2010). 'Strange changes': Indigenous perspectives of climate change and adaptation in NE Arnhem Land (Australia). Global Environmental Change, 20, 681-692.

Race, D. (2015). The impacts of, and strategies to ameliorate, the intensity of climate change on enterprises in remote Australia (CRC for Remote Economic Participation Working Paper CW020). Alice Springs, NT: Ninti One Ltd.

Race, D., Campbell, M., Hampton, K., Foster, D., Fejo, C. \& Robertson, D. (2014). Observations of climate change by remote communities: Lessons from the bush in central Australia. Journal of Australian Indigenous Issues, 17, 23-39.

Race, D., Mathew, S., Campbell, M. \& Hampton, K. (2016). Understanding climate adaptation investments for communities in remote Australia: Experiences from desert communities. Climatic Change, 139(3-4), 461-475.

Sakakibara, C. (2008). 'Our home is drowning': Iñupiat storytelling and climate change in Point Hope, Alaska. Geographical Review, 98, 456-475.

Salmon, E. (2000). Kincentric ecology: Indigenous perceptions of the humannature relationship. Ecologcal Applications, 10(5), 1327-1332.

Steering Committee for the Review of Government Service Provision. (2014). Overcoming Indigenous disadvantage: Key indicators 2014. Canberra, ACT: Productivity Commission. Retrieved from www.pc.gov.au/research/recurring/ overcoming-indigenous-disadvantage/key-indicators-2014

Torres Strait Regional Authority. (2016, June). Torres Strait Adaptation and Resilience Plan 2016-2021. Report prepared by the Environmental Management Program, Torres Strait Regional Authority.

Turner, N. J. \& Clifton, H. (2009). 'It's so different today': Climate change and Indigenous lifeways in British Columbia, Canada. Global Environmental Change, 19, 180-190.

United Nations Development Programme (UNDP). (2009). Human development report 2009. New York, NY: Author. 
Webb, L., Bambrick, H., Tait, P., Green, D. \& Alexander, L. (2014). Effect of ambient temperature on Australian Northern Territory public hospital admissions for cardiovascular disease among Indigenous and non-Indigenous populations. International Journal of Environmental Research and Public Health, 11(2), 1942-1959.

Wise, R. M., Fazey, I., Stafford Smith, M., Park, S. E., Eakin, H. C., Archer Van Garderen, E. R. M. \& Campbell, B. (2014). Reconceptualising adaptation to climate change as part of pathways of change and response. Global Environmental Change, 28, 325-336.

Zander, K. K., Petheram, L. \& Garnett, S. T. (2013). Stay or leave? Potential climate change adaptation strategies among Aboriginal people in coastal communities in Northern Australia. Natural Hazards, 67(2), 591-609. 
This text is taken from Leading from the North: Rethinking Northern Australia Development, edited by Ruth Wallace, Sharon Harwood, Rolf Gerritsen, Bruce Prideaux, Tom Brewer, Linda Rosenman and Allan Dale, published 2021 by ANU Press, The Australian National University, Canberra, Australia.

doi.org/10.22459/LN.2021.19 